\title{
The free maternal health policy: Acceptability and satisfaction with quality of maternal health services during pregnancy in rural Northern Ghana
}

\author{
Philip Ayizem Dalinjong1* , Alex Y. Wang1 , Caroline S. E. Homer²
}

${ }^{1}$ Faculty of Health, University of Technology Sydney, Sydney, Australia, ${ }^{2}$ Burnet Institute, University of Melbourne, Melbourne, Australia

\begin{abstract}
Introduction: Ghana introduced a maternal health policy in July 2008 to provide free of cost health services to women. However, the utilization of services does not depend on affordability alone but acceptability as well. Acceptability includes attitudes and behaviors of providers and satisfaction with the quality of care. The study explored women's views and perceptions about attitudes and behaviors of providers and satisfaction with the quality of services under the free maternal health policy in Ghana. In addition, the views and perceptions of providers were examined.
\end{abstract}

Methods: A convergent parallel mixed methods study was conducted. The study was carried out in the Kassena-Nankana Municipality in Ghana. A structured questionnaire was distributed among women $(n=406)$ who utilized health facilities during pregnancy. Further, focus group discussions (FGDs) with women ( $n=10)$ and in-depth interviews with midwives and nurses $(n=25)$ were held. Quantitative data were analyzed using descriptive statistics, while the qualitative data were recorded, transcribed, read, and coded thematically.

Results: Women perceived facilities to be clean, especially the smaller ones. Ninety-eight percent of women $(n=313 / 320)$ perceived providers to be respectful or friendly, and this was mostly confirmed in the FGDs. More than two-thirds of the women $(74 \%, n=300)$ were also very satisfied or satisfied with the quality of care due to the respect accorded them by providers. Equally, midwives and nurses were satisfied with the quality of care they provided. Nonetheless, providers believed that the unavailability of drugs and supplies, laboratory services, accommodation and transportation for emergencies reduced women's satisfaction with services and the quality of care they could provide.

Conclusion: The services provided to women during pregnancy were acceptable under the free maternal health policy. There remain challenges in addressing a lack of infrastructure and commodities that affects the quality of care.

Key words: National Health Insurance; free maternal health policy; pregnancy; acceptability; health providers' behavior; satisfaction; quality of care; Ghana *Corresponding author: Philip Ayizem Dalinjong, University of Technology Sydney, Building 10, Level 7, Jones Street, Ultimo, NSW 2007
(PO Box 222), Sydney, Australia. E-mail: PhilipAyizem.Dalinjong@student.uts.edu.au

Submitted: 21 June 2019/Accepted: 21 August 2019

DOI: https://doi.org/10.17532/jhsci.2019.745 


\section{INTRODUCTION}

In 2000, the United Nations adopted and ratified the Millennium Development Goals. Goal 5 related specifically to maternal health. The goal was to achieve a three-quarters reduction in the 1990 global maternal mortality rate by the year 2015 , as well as achieve universal access to reproductive health services (1).

Following this, the government of Ghana implemented the free maternal health policy under its National Health Insurance Scheme (NHIS) in July 2008. The NHIS aimed to enhance the utilization of health services for all Ghanaians, while the free maternal health policy sought to improve the use of maternal health services through the elimination of direct cost at the point of utilization. Pregnant women are registered into the scheme without any payment of premium or processing fee. Once registered, women are entitled to free of cost maternal health services and drugs throughout pregnancy, at childbirth and up to 3 months postpartum. It was envisioned that the implementation of the policy will lead to the reduction of maternal deaths in the country as well as help attain universal health coverage.

Health policies or interventions such as the free maternal health policy in Ghana depend on their acceptability by implementers (health workers, and policymakers) and beneficiaries (consumers) for their success (2-4). Acceptability by consumers and providers is key in the design, evaluation, and implementation (4). A recent review of reviews defined acceptability as a "multi-faceted construct that reflects the extent to which people delivering or receiving a health intervention consider it to be appropriate, based on anticipated or experienced cognitive and emotional responses to the intervention" (page 3) (4). If acceptability is absent, services will not be utilized despite the policies or interventions.

A number of factors affect acceptability, including attitudes and expectations of clients and health providers, their personal and social values, religion, culture, gender, autonomy, and the characteristics of the health service as a whole $(5,6)$. In maternal health care, studies have identified other factors affecting acceptability. These include disrespect, physical and verbal abuse, humiliation, rudeness, negligence, poor communication, absenteeism, and lack of empathy for women by health providers (7-11). For instance, a recent study in Lao People's Democratic Republic revealed that some women were humiliated by health providers and hence they chose not to visit or recommend such facilities to other women (12). Apart from bad attitudes and behaviors, the physical environment, cleanliness of health facilities, privacy, comfort, and emotional support also affect the acceptability of maternal health services $(7,13)$. For instance, Srivastava et al. (13) reported in a review that cleanliness was a significant determinant of satisfaction for maternal health services.

Importantly, quality of care determines the uptake and utilization of maternal health services too $(14,15)$. It is a fundamental human right for which all women are entitled to $(16,17)$. As part of this, the World Health Organization (WHO) advocates for the provision of quality health services for all women during pregnancy, childbirth, and postpartum (16). Consequently, the WHO developed a framework for the improvement and monitoring of the quality of care. The framework outlines eight domains classified under two dimensions; the provision and experience of care (Box 1).

The experience of care is critical to meeting these domains; that is, communication and interactions with women and families, respect and preservation of the dignity of women, emotional support, the availability of competent health staff and necessary physical resources including water, electricity, drugs, equipment, and the general environment of health facilities (13). Health providers' satisfaction with the quality of care is also affected by these domains under the provision of care (18-21). Given the key role that quality of care plays in the provision and

BOX 1. Domains for improving and monitoring the quality of maternal health services (16)

\begin{tabular}{|c|c|}
\hline Provision of care & Experience of care \\
\hline $\begin{array}{l}\text { 1. Evidence-based practices of } \\
\text { routine care and management } \\
\text { of complications } \\
\text { 2. Actionable information systems }\end{array}$ & $\begin{array}{l}\text { 4. Effective communication } \\
\text { 5. Respect and } \\
\text { preservation of dignity } \\
\text { 6. Emotional support }\end{array}$ \\
\hline & \\
\hline \multicolumn{2}{|c|}{ 7. Competent, motivated human resources } \\
\hline
\end{tabular}


use of health services, there is the need for it to be advocated for, promoted and monitored $(16,22,23)$.

Under the free maternal health policy in Ghana, limited studies exist on issues relating to acceptability particularly with regard to attitudes and behaviors of health providers toward women during pregnancy. Promoting access to maternal health services, especially to reduce maternal deaths, is not just about affordability, but whether these services address the health needs, rights, dignity, beliefs, and cultural values of pregnant women, including those from poor and minority groups.

To understand the impact of the free maternal health policy on the acceptability of services, the study examined attitudes and behaviors of health providers toward clients as well as overall satisfaction with the quality of maternal health services during pregnancy. The views and perceptions of women, midwives and nurses were explored.

\section{METHODS}

\section{Study design}

A convergent parallel mixed methods study was conducted (24). Convergent parallel mixed methods allow for the researcher to converge or combine both quantitative and qualitative data together to ensure a comprehensive analysis of a research question (24). The quantitative and qualitative data were collected in parallel and analyzed independently. The results were finally integrated to answer the study question on acceptability and satisfaction with the quality of care.

The quantitative part of the study consisted of a survey of women who used maternal health services during pregnancy. The qualitative aspect also involved focus group discussions (FGDs) with women who used maternal health services during pregnancy. In-depth interviews (IDIs) were held with health providers (midwives and nurses) as well. Ethical approval for the conduct of the study was obtained from the ethics review boards of the Navrongo Health Research Centre and the University of Technology Sydney (UTS) (approval numbers NHRCIRB217 and ETH16-0263, respectively). Informed consent was received from all participants of the study. Written permission was also taken from directors of the Ghana Health Service in charge of the study district and region. Health facility managers gave their approval for the study to be carried out in the facilities.

\section{Study area}

The study was carried out in the Kassena-Nankana Municipality. It is one of the 13 districts and municipalities in the Upper East region of Northern Ghana, with Navrongo as its capital. The municipality was purposefully selected due to financial constraints to conduct the study, elsewhere. According to a report by the Ghana Health Service, the municipality had a projected population of 130,593 in 2017 , compared to a population of $1,244,983$ for the region (25). For the same year, women in fertile age (WIFA) were estimated to be 31,342 , while that for the region was 298,796 (25). Economically, the municipality is considered rural and poor, bearing resemblance to other poor districts and municipalities in Ghana and across Africa (26).

The municipality has a total of 24 health facilities providing health services to the people. The health facilities include one hospital, two health centers, three clinics, and 18 Community-Based Health Planning and Services (CHPS) (also known as CHPS compounds). The CHPS compounds are the lower-level health facilities located in distant and remote communities. A small number of the CHPS compounds have been provided with basic infrastructure in terms of a laboratory, delivery room, dispensary, etc., for the provision of maternal health services. Most of them (CHPS compounds) are without these facilities and thus tend to refer women when the need arises, especially for blood testing and scans.

\section{Study participants}

Gorstein's et al. (27), the formula for sample size calculation using a proportion in a single cross-sectional survey was adopted and used. This gave a required sample size of 388 women who utilized health facilities during pregnancy. A total of 406 women were recruited to account for possible withdrawals. For the qualitative aspect of the study, 10 FGDs and 25 IDIs were held with women and 
health providers, respectively. Women were invited to participate in the FGDs. The IDIs were held with midwives and nurses, who provided maternal health services to women.

\section{Data instruments}

The questions for the survey focussed on factors affecting acceptability; comprising the cleanliness of health facilities, and respectfulness/friendliness of health providers toward clients. Overall satisfaction with the quality of care on the part of women and health providers were also captured. The survey was developed specifically for this study.

Quality of care has two attributes, technical and interpersonal, or perceived quality (28). Perceived quality of care was measured, since increased utilization of maternal health services does not only depend on technical quality but also on acceptability and patient-centredness across the continuum of care (29). Women were required to state their overall satisfaction with the quality of care by selecting one of the options "very satisfied," "satisfied," "normal," "dissatisfied," and "very dissatisfied."

Interview guides were developed for the FGDs and IDIs. These also focused on the attitudes and behavior of health providers and the overall satisfaction with the quality of care. Midwives and nurses were asked to indicate their overall satisfaction with the quality of care and the reasons for that. Both interviews guides were developed in English, but the one for the FGDs was translated by language experts into the two local dialects (Kasem and Nankam) spoken in the municipality. The translated version was used for the FGDs with the women. The guide for the IDIs was not translated because midwives and nurses spoke and understood English. All questions were piloted among women and health providers and changes made where necessary. Data were collected from March 2016 to August 2016.

\section{Recruitment of study participants}

Women were recruited for the quantitative part of the study in health facilities $(n=353)$ as well as at the homes of women $(n=53)$. This was done to assist capture the views of both categories of women (that is, women who gave birth in health facilities and those who gave birth at home but had used health services during pregnancy). All health facilities offering maternal health services in the study area were visited daily by research assistants. Women who had given birth and had been discharged to go home were approached for participation in the study. With their consent, these women were interviewed. The contact details of women who had given birth at home recently were retrieved from the Navrongo Health Research Center. Registers of postnatal services were also utilized to collect contact details of women who gave birth at home but visited health facilities for postnatal services. These contact details were used to trace women at their various homes for recruitment. Women who had given birth at home before January 1, 2016, were excluded from the study. This was done to reduce recall bias. Each interview lasted 30-45 min.

The same category of women participated in the FGDs. The recruitment was done at health facilities when women visited for postnatal services. The discussions were held in the health facilities, in the absence of midwives and nurses each FGD comprised 5-12 women.

Midwives and nurses were contacted and invited to participate in the IDIs. After consent, the IDIs were held in the health facilities. To promote privacy, all interviews were held in rooms without the presence of other health workers. All FGDs and IDIs were recorded with the permission of the participants. Field notes were also taken. All FGDs and IDIs were conducted by the main investigator.

The investigator made a summary of the pertinent issues after each discussion or interview and submitted these back to participants for their approval or rejection. The investigator also continuously updated the interview guides with new key issues that emerged in previous discussions or interviews. Each discussion or interview ended when participants agreed that they had nothing further to discuss after prompts from the investigator. This was considered as the point of data saturation for each discussion or interview. It took about 45-120 min to conduct each discussion or interview depending on the number of participants (in the FGDs) as well as the depth of the discussion. 


\section{Data analysis and management}

The survey data were electronically collected using the Survey CTO Collect v2.10 application. The SurveyCTO Collect application works on handheld gadgets allowing for the capture, processing, and transport of data for analysis. The cleaning and analysis of the data were done in STATA 14. The findings were presented using descriptive statistics.

The recordings of the FGDs and IDIs were translated and transcribed verbatim. An initial reading of the transcripts and field notes was done for familiarization with the data. Audiotapes were also selected and listened to in comparison with their transcripts to ensure the validity and accuracy of the transcription. Any observed difference between the audio recordings and the transcripts were corrected before the coding of the data. Subsequently, all transcripts were thoroughly reviewed for the identification of key issues. A coding system was then developed based on the review, highlighting themes and sub-themes relating to providers' behavior and quality of care. The themes and sub-themes were written out in text tables including essential quotes from participants. The presentation of the findings followed the themes and sub-themes that emerged from the data.

\section{RESULTS}

\section{Background characteristics of women for the survey}

Four hundred and six women completed the survey with a mean age of 27 years. Just under one-third of women $(31.3 \%, \mathrm{n}=127)$ was $<29$ years of age (Table 1). One in three women $(31.5 \%, \mathrm{n}=128)$ had experienced childbirth for the first time. Almost all $(99 \%, n=402)$ women had four or more antenatal visits during pregnancy.

\section{Perception of the cleanliness of health facility during pregnancy}

The majority $(93.6 \%, \mathrm{n}=380)$ of the women stated the health facilities were clean or very clean. In the FGDs, the women perceived the smaller health facilities (CHPS compounds) to be cleaner than the main larger hospital. A woman said:
TABLE 1. Background characteristics of women in Kassena-Nankana Municipality (Upper East region), March-August 2016

\begin{tabular}{|c|c|c|}
\hline Categories & $\mathrm{n}$ & $\%$ \\
\hline \multicolumn{3}{|l|}{ Age } \\
\hline$<20$ & 41 & 10.0 \\
\hline $20-24$ & 103 & 25.4 \\
\hline $25-29$ & 127 & 31.3 \\
\hline $30-39$ & 120 & 29.6 \\
\hline $40+$ & 15 & 3.7 \\
\hline \multicolumn{3}{|l|}{ Marital status } \\
\hline Single & 20 & 4.9 \\
\hline Married & 386 & 95.1 \\
\hline \multicolumn{3}{|l|}{ Educational level } \\
\hline No formal education & 64 & 15.8 \\
\hline Primary/Junior High School & 226 & 55.7 \\
\hline Senior High/Technical school & 67 & 16.5 \\
\hline Tertiary institution & 49 & 12.0 \\
\hline \multicolumn{3}{|l|}{ Occupation } \\
\hline Unemployed & 29 & 7.1 \\
\hline Trader & 79 & 19.5 \\
\hline Farmer & 155 & 38.2 \\
\hline Public/Civil servant & 46 & 11.3 \\
\hline Student & 42 & 10.3 \\
\hline Other & 55 & 13.6 \\
\hline \multicolumn{3}{|l|}{ Religion } \\
\hline Traditional & 20 & 4.9 \\
\hline Catholic & 164 & 40.4 \\
\hline Protestant & 192 & 47.3 \\
\hline Muslim & 30 & 7.4 \\
\hline \multicolumn{3}{|l|}{ Ethnicity } \\
\hline Kasem & 239 & 58.9 \\
\hline Nankam & 135 & 33.2 \\
\hline Other & 32 & 7.9 \\
\hline \multicolumn{3}{|l|}{ Number of births } \\
\hline 1 & 128 & 31.5 \\
\hline 2 & 103 & 25.4 \\
\hline 3 & 79 & 19.5 \\
\hline 4 or more & 96 & 23.6 \\
\hline
\end{tabular}

"Yes, here (CHPS compound) there is no more dirt like in the hospital" (FGD, woman).

Helping to explain why the smaller health facilities are cleaner than the main hospital, a nurse indicated:

"Our facility is small, so it is easy to manage and keep it neat" (IDI, nurse). 


\section{Respectfulness and friendliness of health providers toward women}

The study measured the respectfulness and friendliness of health providers toward women. Approximately $97.8 \%(n=313 / 320)$ of the women perceived health providers to be respectful and friendly (Table 2). Twenty-six women thought health providers were disrespectful or very disrespectful as well as unfriendly or very unfriendly.

The FGDs with the women confirmed this finding. The women reported that health providers were friendly during their encounter. A woman reported:

"They respect us (here), there are some clinics that when you go they will not respect you because they are nurses and we are nothing" (FGD, woman).

Equally, the IDIs with the midwives and nurses confirmed the positive attitude and behavior of health providers in some of the health facilities. A nurse said:

"Because I think in this facility, some women even come from far to attend their antenatal care and postnatal here not because everything is here, but the environment to some extent is friendly here" (IDI, nurse).

The midwives and nurses explained that the number of clients attending a health facility largely depends on the attitude and behavior of health providers. If the health providers' attitude and behavior in a particular health facility are friendly or welcoming, more women would attend that health facility. A midwife explained:

"...to be able to know whether you are behaving well or not will depend on the number of people who come to see you. If you are not behaving well toward clients you wouldn't get clients, they will walk away because the facilities are now many so they don't need to be forced at a place, they have plenty choices to make" (IDI, midwife).

A few of the women in the FDGs indicated that they had experienced a hostile behavior from some health providers. This is especially the case in the smaller health facilities (CHPS compounds) where the women had to receive health services from other health providers in the absence of the main midwife. A woman reported:

\section{"When I was pregnant I came with a complaint and the midwife ask me to go for scan, on my return she was absent but asked me to see those nurses, but they only took the results and laugh and threw the results at me, so I call the midwife and she told me I should go and come the next day because she was on leave, and when I came the next day the nurses treated me the same way, so I left the center" (FGD, woman).}

Some midwives and nurses also attested to the unfriendliness of some of the health providers. A nurse said:

"In my view, talking of staff attitude, some of us, we're very horrible. So it scares some mothers away from us" (IDI, nurse).

\section{Women's overall satisfaction with the quality of services during pregnancy}

The women were asked about their overall satisfaction with the quality of maternal health services received during pregnancy. Seventy-four percent $(n=300)$ of the women were very satisfied or satisfied with the quality of maternal health services (Figure 1). A small number of women $(2.9 \%, \mathrm{n}=12)$

TABLE 2. Respectfulness and friendliness of health providers toward women in Kassena-Nankana municipality (Upper East region), March-August 2016

\begin{tabular}{|c|c|c|c|c|c|c|c|c|c|c|}
\hline \multirow[t]{3}{*}{ Respectful } & \multicolumn{10}{|c|}{ Friendliness } \\
\hline & \multicolumn{2}{|c|}{ Very friendly } & \multicolumn{2}{|c|}{ Friendly } & \multicolumn{2}{|c|}{ Normal } & \multicolumn{2}{|c|}{$\begin{array}{l}\text { Unfriendly or very } \\
\text { unfriendly }\end{array}$} & \multicolumn{2}{|r|}{ Total } \\
\hline & n & $\%$ of total & $n$ & $\%$ of total & $\mathrm{n}$ & $\%$ of total & $n$ & $\%$ of total & $n$ & $\%$ of total \\
\hline Very respectful & 42 & 97.7 & 3 & 0.9 & 0 & 0.0 & 0 & 0.0 & 45 & 11.1 \\
\hline Respectful & 1 & 2.3 & 313 & 97.8 & 1 & 5.9 & 0 & 0.0 & 315 & 77.7 \\
\hline Normal & 0 & 0.0 & 1 & 0.3 & 15 & 88.2 & 0 & 0.0 & 16 & 3.9 \\
\hline Disrespectful/very disrespectful & 0 & 0.0 & 3 & 0.9 & 1 & 5.9 & 26 & 100 & 30 & 7.4 \\
\hline Total & 43 & 10.6 & 320 & 78.8 & 17 & 4.2 & 26 & 6.4 & 406 & 100 \\
\hline
\end{tabular}




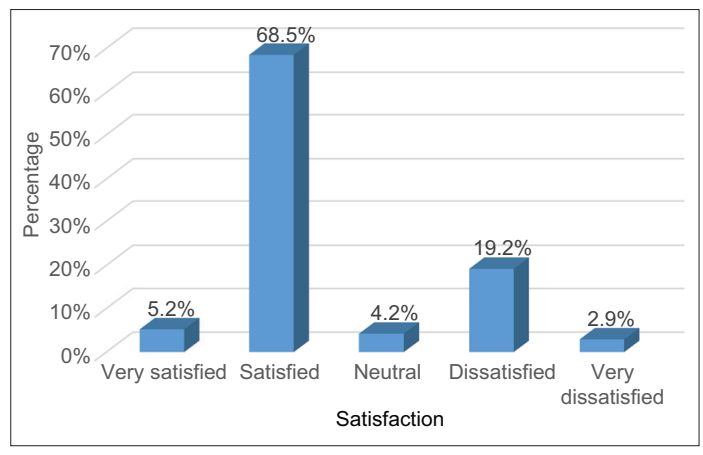

FIGURE 1. Women's overall satisfaction with the quality of services during pregnancy in Kassena-Nankana Municipality (Upper East region), March-August 2016.

reported that they were very dissatisfied with the quality of maternal health services.

The FGDs with the women supported these perceptions. Overall, the women reported being satisfied with the quality of maternal health services received during pregnancy. This is because health providers showed respect and empathy for the women. A woman said:

"I am satisfied because she (midwife) is respectful and has sympathy for human beings" (FGD, woman).

Most women would recommend that their relatives and other people make use of maternal health services in the health facilities. A woman reported:

"I will also advise my relatives to come to this facility" (FGD, woman).

In addition, the midwives and nurses concurred that the women who sought their services were satisfied. A midwife explained:

"But I can boldly say some [women] are really satisfied and they keep reminding us of the good things that we have done" (IDI, midwife).

\section{Providers' overall satisfaction with the quality of maternal health services during pregnancy}

In the IDIs, most of the midwives and nurses indicated that they were satisfied with the quality of maternal health services they were able to provide to women. A midwife said:

"I'm satisfied with the services provided to the women, because it's not that bad. It's not very bad at all" (IDI, midwife).
There remain challenges that affect the provision of health services during pregnancy. These included the unavailability of drugs and supplies, laboratory services, accommodation, and transportation for emergency referrals. A midwife stated:

"Weve problems with regard to accommodation, drugs and supplies, labs, and all that - we are not very happy providing maternal health services with these challenges" (IDI, midwife).

As a result of these challenges, health providers were unable to provide services to clients, especially in some CHPS compounds. Thus, the midwives and nurses were not fully satisfied with the quality of maternal health services.

\section{DISCUSSION}

The study showed that women perceived health facilities to be clean, especially the smaller ones (the CHPS compound). About 97.8\% ( $n=313 / 320)$ of the women perceived health providers to be respectful and friendly, which was confirmed in the FGDs and IDIs. A few of the women in the FGDs were not happy with the behavior of health providers and this would likely impact their future use of services or recommendations to others. Overall, $74 \%$ of the women $(n=300)$ were very satisfied or satisfied with the quality of care. The midwives and nurses were also satisfied with the overall quality of care provided. The unavailability of drugs and supplies, laboratory services, accommodation and transportation for emergencies meant that health providers felt that they were not able to provide quality services.

Valuing the cleanliness of health facilities is consistent with other studies. For example, a survey conducted in rural South India in government and private health facilities showed that over $80 \%$ of the participants were happy with the cleanliness and comfort of health facilities providing maternal health services (30). Similarly, in Bangladesh, participants in a mixed methods study indicated they were satisfied with the cleanliness of the health facilities (31). Our finding might be explained by the fact that the majority of the health facilities where the study took place were small in size and hence easier to keep clean as reported. A level of cleanliness in the health facilities seems to be one of the key indicators for the perception of quality (7). Perhaps 
because it is also easily observed and measured by clients.

Our study demonstrated that health providers were perceived to be respectful and friendly toward women during pregnancy, and this drives utilization. Other studies have reported similar findings $(7,12,32)$. In Nnewi, Nigeria, women were found to be satisfied with the attitudes and behaviors of health providers (33). In the Lao People's Democratic Republic, women also expressed happiness with the behavior of health providers (12). Given that the majority of the study health facilities were smaller ones, it was possible to develop interpersonal relationships and continuity of care, necessary for a positive experience of care and satisfaction $(7-11,13)$

Over two-thirds of the women $(74 \%)$ in the survey reported overall satisfaction with the quality of maternal health services. Findings from the FGDs and IDIs also supported the survey. Women showed overall satisfaction with the services received due to the respect health providers had for them and thus willing to make recommendation to other women. Likewise, studies in Bangladesh and India have found women to be satisfied with the quality of maternal and child health services because of cleanliness, short waiting times, and long consultation time with health providers $(31,34)$. In Anambra State, Southeast Nigeria, women utilizing ANC services reported high satisfaction with the quality of maternal health services as a result of the good attitude of health providers (35). However, these studies in Bangladesh, India, and Nigeria were not specifically conducted under fee exemption policies and hence differ in context from our study. Our finding is in line with the vision of the WHO that "health care staff treat all women with kindness, compassion, courtesy, respect, understanding, and honesty and preserve their dignity" without regard to the background (page 48) (16). It seems evident that training and support of staff had considerable success in the provision of respectful care.

Most of the midwives and nurses were satisfied with the quality of maternal health services as well. The midwives and nurses explained that women continuously reminded them of the good work carried out for pregnant women. That pregnant women also showed high patronage for some health facilities, which is indicative of good provider relations and quality of care provision. This finding confirmed a study among midwives in an urban hospital in South Ghana, which showed midwives to have rated the quality of maternal health services under the focused antenatal care to be good (36). Although the study and ours were carried out under the free maternal health policy, the study settings were different. Study was conducted in only one urban hospital in South Ghana, while our study was conducted in one rural hospital and several CHPS compounds and health centers in North Ghana. Economically, South Ghana is more endowed than North Ghana. The documented satisfaction with the quality of care by both clients and health providers might be another evidence of the acceptability of maternal health services under the free maternal health policy. Although it might be that women do not know how good care could be, the finding might be a good precursor for the achievement of universal health coverage in the future.

Notwithstanding, the midwives and nurses highlighted challenges hindering the full provision of quality services to women. Among these were the unavailability of drugs and supplies, laboratory services, accommodation, and transportation for emergencies. The lack of drugs, supplies, and laboratory services might make women incur some costs when using services (37). Women might be required to buy some drugs as well as carry out certain tests that would require their payment. Besides, the unavailability of accommodation within health facilities would not permit providers to stay in and provide services at all times of the day/night for pregnant women. In addition, the lack of transport for emergencies hinders the immediate referral of women in critical need of emergency obstetric care. This challenge could lead to deaths and bad birth outcomes among women $(38,39)$. Therefore, to fully provide services to women under the free maternal health policy, policymakers, and other stakeholders in the health sector need to address these challenges. The Government of Ghana and donors in particular, will have to focus on providing more financial support for the construction and provision of infrastructure and logistics for the provision of maternal health services. 


\section{Study limitations}

The findings for this study might be influenced by the "halo effect," especially for the women who were interviewed in health facilities immediately after their childbirth. The joy of having a live and healthy child may mean that women are less likely to express any negative sentiments against health providers and facilities $(40,41)$. First time mothers might have different perceptions, compared to women with the previous history of childbirth in health facilities (40), since $32 \%$ of the women in our study were first time mothers. Equally, if women have not experienced quality care, they might not know what it is. Besides, this study was conducted in only one municipality in rural North Ghana. There are 216 metropolitans, municipal and district areas in Ghana and hence the findings of the study might not be generalizable to other settings in the country. Thus, the findings of the study should be interpreted with these in mind. Nevertheless, the study has demonstrated the acceptability of maternal health services during pregnancy in the study area, which is essential for the success of health policies or interventions like the free maternal health policy (2-4).

\section{CONCLUSION}

Health facilities, especially smaller ones, offering maternal health services were perceived to be cleaned. Health providers were also perceived to be very respectful and friendly to women. Finally, the study documented women and health providers' overall satisfaction with the quality of maternal health service, despite some challenges such as the lack of drugs and supplies, laboratory services, accommodation, and transportation for emergencies. There is the acceptability of maternal health services, given the overall satisfaction with quality. These findings are encouraging as it shows that a material health policy can be implemented to provide acceptable care. Action is needed to tackle the challenges highlighted by the midwives and nurses affecting the provision of quality care.

\section{CONFLICTS OF INTEREST}

The authors declare that they have no conflicts of interest.

\section{ACKNOWLEDGMENT}

The UTS awarded two scholarships; (UTS International Research Scholarship and UTS President's Scholarship) to enable the first author to pursue a doctoral degree in UTS. The UTS WHO Collaborating Centre in Nursing, Midwifery, and Health also provided a travel award for data collection for the PhD.

We are thankful to all participants for providing information for this study.

\section{REFERENCES}

1. The United Nations. Trends in Maternal Mortality: 1990 to 2015: Estimates by WHO, UNICEF, UNFPA, World Bank Group and the United Nations Population Division. Geneva: The United Nations; 2015.

https://doi.org/10.1111/padr.12033.

2. Diepeveen S, Ling T, Suhrcke M, Roland M, Marteau TM. Public acceptability of government intervention to change health-related behaviours: A systematic review and narrative synthesis. BMC Public Health 2013;13:756. https://doi.org/10.1186/1471-2458-13-756.

3. Stok FM, de Ridder DT, de Vet E, Nureeva L, Luszczynska A, Wardle J, et al. Hungry for an intervention? Adolescents' ratings of acceptability of eating-related intervention strategies. BMC Public Health 2016;16(1):5.

https://doi.org/10.1186/s12889-015-2665-6.

4. Sekhon M, Cartwright M, Francis JJ. Acceptability of healthcare interventions: An overview of reviews and development of a theoretical framework. BMC Health Serv Res 2017;17(1):88.

https://doi.org/10.1186/s12913-017-2031-8.

5. Peters DH, Garg A, Bloom G, Walker DG, Brieger WR, Rahman MH. Poverty and access to health care in developing countries. Ann N Y Acad Sci 2008;1136:161-71.

https://doi.org/10.1196/annals.1425.011.

6. Levesque JF, Harris MF, Russell G. Patient-centred access to health care: Conceptualising access at the interface of health systems and populations. Int J Equity Health 2013;12:18.

https://doi.org/10.1186/1475-9276-12-18.

7. Grigoryan R, Ruzanna Z, Sacci I. Women's Perception of Quality of Maternal and Child Health Services: Results of Qualitative Research Study in Project Nova-Supported Networks. United States: USAID Project NOVA; 2008.

8. Holmes D. Margaret Chan: Committed to universal health coverage. Lancet 2012;380(9845):879.

https://doi.org/10.1016/s0140-6736(12)61493-7.

9. Bohren MA, Hunter EC, Munthe-Kaas HM, Souza JP, Vogel JP, Gülmezoglu AM. Facilitators and barriers to facility-based delivery in low- and middle-income countries: A qualitative evidence synthesis. Reprod Health 2014;11(1):71.

https://doi.org/10.1186/1742-4755-11-71.

10. Mannava P, Durrant K, Fisher J, Chersich M, Luchters S. Attitudes and behaviours of maternal health care providers in interactions with clients: A systematic review. Global Health 2015;11:36.

https://doi.org/10.1186/s12992-015-0117-9.

11. Bowser D, Hill K. Exploring Evidence for Disrespect and Abuse in FacilityBased Childbirth: Report of a Landscape Analysis, USAID/TRAction Project. The United States: Harvard School of Public Health, University Research Company, LLC; 2010. 
12. Ngan do K, Kang M, Lee C, Vanphanom S. "Back to basics" approach for improving maternal health care services utilization in lao PDR. Asia Pac J Public Health 2016;28(3):244-52.

https://doi.org/10.1177/1010539516634188.

13. Srivastava A, Avan BI, Rajbangshi P, Bhattacharyya S. Determinants of women's satisfaction with maternal health care: A review of literature from developing countries. BMC Pregnancy Childbirth 2015;15:97. https://doi.org/10.1186/s12884-015-0525-0.

14. Hutchinson PL, Do M, Agha S. Measuring client satisfaction and the quality of family planning services: A comparative analysis of public and private health facilities in Tanzania, Kenya and Ghana. BMC Health Serv Res 2011;11(1):203. https://doi.org/10.1186/1472-6963-11-203.

15. Osariemen GA. Theoretical issues in the understanding of maternal health services utilization in Lagos state, Nigeria. Eur J Soc Sci 2011;22(3):431.

16. World Health Organization. Standards for Improving Quality of Maternal and Newborn Care in Health Facilities. Geneva: World Health Organization; 2016.

17. International Federation of Gynecology and Obstetrics, International Confederation of Midwives, White Ribbon Alliance, International Pediatric Association, World Health Organization, International Federation of Gynecology and Obstetrics. Mother-baby friendly birthing facilities. Int J Gynaecol Obstet 2015;128(2):95-9

https://doi.org/10.1016/j.jiggo.2014.10.013.

18. Kiguli J, Ekirapa-Kiracho E, Okui O, Mutebi A, Macgregor H, Pariyo GW. Increasing access to quality health care for the poor: Community perceptions on quality care in Uganda. Patient Prefer Adherence 2009;3:77-85. https://doi.org/10.2147/ppa.s4091.

19. Mosadeghrad AM. Factors influencing healthcare service quality. Int $J$ Health Policy Manag 2014;3:77-89. https://doi.org/10.15171/ijhpm.2014.65.

20. Penfold S, Shamba D, Hanson C, Jaribu J, Manzi F, Marchant T, et al. Staff experiences of providing maternity services in rural southern Tanzania - a focus on equipment, drug and supply issues. BMC Health Serv Res 2013;13:61. https://doi.org/10.1186/1472-6963-13-61.

21. Tunçalp Ö, Were WM, MacLennan C, Oladapo OT, Gülmezoglu AM, Bahl R, et al. Quality of care for pregnant women and newborns-the WHO vision. BJOG 2015;122(8):1045-9.

https://doi.org/10.1111/1471-0528.13451.

22. Tooker J, Ambulatory Care Quality Alliance. The importance of measuring quality and performance in healthcare. MedGenMed 2005;7(2):49.

23. Gupta KS, Rokade V. Importance of quality in health care sector. J Health Manag 2016;18:84-94.

24. Creswell JW. Research Design: Qualitative, Quantitative and Mixed Methods Approaches. $4^{\text {th }}$ ed. Washington DC: SAGE Publication Inc.; 2014.

25. Ghana Health Service. The Health Sector in Ghana-Facts and Figures 2018. Accra: Ghana Health Service, Policy Planning MaEDP; 2018.

26. Ghana Statistical Service. Ghana Poverty Mapping Report. Accra: Ghana Statistical Service; 2015.

27. Gorstein J, Sullivan KM, Parvanta I, Begin F. Indicators and Methods for Cross-Sectional Surveys of Vitamin and Mineral Status of Populations. The Micronutrient Initiative (Ottawa) and the Centers for Disease Control and Prevention (Atlanta). Atlanta: Centers for Disease Control and Prevention; 2007
28. Donabedian A. Criteria, norms and standards of quality: What do they mean? Am J Public Health 1981;71(4):409-12.

https://doi.org/10.2105/ajph.71.4.409.

29. Hanefeld J, Powell-Jacksona T, Balabanovaa D. Understanding and measuring quality of care: Dealing with complexity. Bull World Health Organ 2017;95(5):368-74.

https://doi.org/10.2471/blt.16.179309.

30. Ganguly E, Sharma PK. Client satisfaction with quality of health care in a rural area in Southern India. J Public Health Epidemiol 2014;6(8):239-45. https://doi.org/10.5897/jphe2014.0625.

31. Islam F, Rahman A, Halim A, Eriksson C, Rahman F, Dalal K. Perceptions of health care providers and patients on quality of care in maternal and neonatal health in fourteen Bangladesh government healthcare facilities: A mixed-method study. BMC Health Serv Res 2015;15:237. https://doi.org/10.1186/s12913-015-0918-9.

32. Mahiti GR, Mkoka DA, Kiwara AD, Mbekenga CK, Hurtig AK, Goicolea I. Women's perceptions of antenatal, delivery, and postpartum services in rural Tanzania. Glob Health Action 2015;8(1):28567.

https://doi.org/10.3402/gha.v8.28567.

33. Nnebue CC, Ebenebe UE, Adinma ED, lyoke CA, Obionu CN, llika AL. Clients' knowledge, perception and satisfaction with quality of maternal health care services at the primary health care level in Nnewi, Nigeria. Niger J Clin Pract 2014;17(5):594-601.

https://doi.org/10.4103/1119-3077.141425.

34. Das P, Basu M, Tikadar T, Biswas G, Mridha P, Pal R. Client satisfaction on maternal and child health services in rural bengal. Indian J Community Med 2010;35(4):478-81. https://doi.org/10.4103/0970-0218.74344.

35. Emelumadu OF, Onyeonoro UU, Ukegbu AU, Ezeama NN, Ifeadike CO, Okezie OK. Perception of quality of maternal healthcare services among women utilising antenatal services in selected primary health facilities in Anambra state, Southeast Nigeria. Niger Med J 2014;55:148-55. https://doi.org/10.4103/0300-1652.129653.

36. Baffour-Awuah A, Mwini-Nyaledzigbor PP, Richter S. Enhancing focused antenatal care in Ghana: An exploration into perceptions of practicing midwives. Int J Afr Nurs Sci 2015;2:59-64.

https://doi.org/10.1016/j.ijans.2015.02.001.

37. Chowdhury S, Hossain SA, Halim A. Assessment of quality of care in maternal and newborn health services available in public health care facilities in Bangladesh. Bangladesh Med Res Counc Bull 2009;35:53-6. https://doi.org/10.3329/bmrcb.v35i2.3044.

38. Raj SS, Manthri S, Sahoo PK. Emergency referral transport for maternal complication: Lessons from the community based maternal death audits in Unnao district, Uttar Pradesh, India. Int J Health Policy Manag 2015;4:99-106

https://doi.org/10.15171/ijhpm.2015.14.

39. IMCIBO. Improving birth outcomes: Meeting the challenge in the developing world. In: Bale JR, Stoll BJ, Lucas AO, editors. Reducing Materna Mortality and Morbidity. Washington DC: National Academies Press; 2003.

40. Paudel YR, Mehata S, Paudel D, Dariang M, Aryal KK, Poudel P, et al. Women's satisfaction of maternity care in Nepal and its correlation with intended future utilization. Int J Reprod Med 2015;2015(783050):9. https://doi.org/10.1155/2015/783050.

41. Séguin $L$, Therrien $R$, Champagne $F$, Larouche $D$. The components of women's satisfaction with maternity care. Birth 1989;16(3):109-13. https://doi.org/10.1111/j.1523-536x.1989.tb00878.x. 